Florez, L., and Cortissoz, J.C. (2017). "Probability Density Function for Predicting Productivity in Masonry Construction Based on the Compatibility of a Crew". In: LC3 2017 Volume II - Proceedings of the 25th Annual Conference of the International Group for Lean Construction (IGLC), Walsh, K., Sacks, R., Brilakis, I. (eds.) pp.655-662. DOI : https://doi.org/10.24928/2017/0261

\title{
PROBABILITY DENSITY FUNCTION FOR PREDICTING PRODUCTIVITY IN MASONRY CONSTRUCTION BASED ON THE COMPATIBILITY OF A CREW
}

\author{
Laura Florez ${ }^{1}$, Jean C. Cortissoz ${ }^{2}$
}

\begin{abstract}
During the different phases of a masonry project, contractors collect detailed information about the labor productivity of its workers and the factors that influence productivity. Information includes quantitative data such as hours, activities, and tasks, and qualitative data such as ratings and personality factors. Personality factors have been found to be a key aspect that influences the compatibility of a crew and the productivity in masonry construction. This paper proposes a mathematical framework to determine how the compatibility between the workers in a crew can be used to predict productivity. A standard method for quantifying personality is used to determine the compatibility of a crew and empirically define a probability density to predict productivity. The probability density determines, for a given compatibility, the average productivity for a crew. The most interesting part of this probability density is that it accounts for variations in the productivity, resulting from the interaction and the relationships between the workers in a crew. The proposed probability distribution can be used to make more realistic predictions, by calculating confidence intervals, of the productivity of masonry crews and to better estimate times of construction, avoid crew conflicts, and find practical ways to increase production.
\end{abstract}

Keywords: masonry construction, productivity, process improvement, crew formation, probability density

\section{INTRODUCTION}

Personality factors have been demonstrated to be useful for explaining and predicting attitudes, behaviors, job performance, and outcomes in many organizational settings (Ones et al, 2007; Shuck and Reio, 2013; Hogan and Holland, 2003; Campion et al, 2005; Cohen and Bailey, 1997). The big five personality dimensions (Goldberg, 1993) are: openness to experience $(\mathrm{O})$, conscientiousness $(\mathrm{C})$, extraversion $(\mathrm{E})$, agreeableness $(\mathrm{A})$, and neuroticism $(\mathrm{N})$, commonly known as OCEAN, and are used to indicate human personality (Ones et al, 2007). The OCEAN dimensions have been investigated in meta-analytic studies (Hogan and Holland, 2003; Cohen and Bailey, 1997), and have been used in applied psychology and human resource management to determine the relationship between personality and job performance. Results of these studies have shown that organizations use personality factors not only for recruitment and personnel selection, but also to support

1 Senior Lecturer, Faculty of Engineering and Environment, Northumbria University, Newcastle Upon Tyne, UK, NE18ST, laura.florez@northumbria.ac.uk

2 Associate Professor, Department of Mathematics, Universidad de Los Andes, Bogotá, Colombia, jcortiss@uniandes.edu.co 
decision making when forming effective groups of workers (Kristof-Brown and Stevens, 2001).

In construction, groups of workers are known as crews. Crews specialize in a given skill to complete a task ( $\mathrm{Ng}$ and Tang, 2010), and the foreman in the jobsite is responsible of forming crews to maximize productivity. Crew formation is the process of determining the size and the composition of each crew to complete a project (Hassanein and Melin, 1997). Decisions on how to form crews and what is the proper grouping of workers to increase productivity in construction have been addressed by a number of studies (Nerwal and Abdelhamid, 2012; Mitropoulos and Memarian, 2012; Hassanein and Melin, 1997; Rojas 2008). These studies provide clear guidelines and specific characteristics that need to be considered to form lean and effective crews.

However, the current crew formation literature in construction lacks of a framework that considers personality factors and how the interpersonal compatibility between workers in a crew can be used to form effective crews and predict productivity. This paper proposes a mathematical framework to determine how the compatibility between workers in a crew can be used to predict productivity. A probability density is empirically defined to predict productivity. The probability density determines, for a given compatibility, the average productivity for a crew and can be used to better estimate times of construction.

\section{CREW FORMATION}

\subsection{Essential concepts}

Crew formation is one of the key tasks in construction project management (Hassanein and Melin, 1997). The process of selecting the workers in a crew is crucial for ensuring the success of a construction project and improved labor productivity. Crew formation is the process of determining the size and the composition of each crew to complete a project (Mitropoulos and Memarian, 2012). The composition of a crew impacts directly the estimating and scheduling process in construction because it has a direct relation with task durations and labor costs and consequently with the productivity of a construction project (Nerwal and Abdelhamid, 2012).

\subsection{Forming masonry crews}

Crews in masonry are formed considering not only time and cost constraints but also considering the characteristics of the masons. Masons have different skills, abilities and personalities and typically the foreman in the jobsite considers these characteristics when forming its crews. By considering these characteristics, the foreman tries to maximize productivity by assigning the proper mason to the proper wall (Florez, 2015). The skills of a mason are considered to either assign a mason to a wall that has many details and cuts or to a wall that has little details. The abilities are considered to either assign a mason to a brick wall or a block wall. The personality is considered to assign a mason to a crew with masons that have similar characteristics rather than to a crew with masons that have dissimilar characteristics.

Personality has been found to be a key aspect that influences the composition of masonry crews. Personality not only influences the interpersonal compatibility between the masons in a crew, but also has a major impact on the performance of a crew which directly affects its productivity (Florez, 2015). A number of studies have been developed to determine the personality factors and preferences that need to be considered to form effective groups in construction such as good communication and confidence (Hiyasatt et 
al, 2016), consensus and heterogeneity (Mach and Barush, 2015), teamwork coordination (Mitropolous and Memarian, 2012), team motivation and satisfaction (Nerwal and Abdelhamid, 2012; Borcherding and Alarcon, 1991), and good relation with workmates (Kazaz and Ulubeyli, 2007) among others. An interesting approach to personality for electrical works can be found compiled in a book edited by Rojas (2008). However, there is no study that has attempted to evaluate and quantify the impact that personal compatibility has on the configuration of crews and whether compatibility can be used to predict productivity.

\section{PERSONALITY FACTORS}

\subsection{The Big Five personality dimensions}

It is well known that group work is organized by determining what will be done and who will do it and in this process, group members make a big effort to get along (Mach and Baruch, 2015). In order to get along with a group, people cooperate and seem compliant, friendly, and positive, and people that get along usually have similar personality factors. The big five personality dimensions OCEAN are used to describe human personality (Ones et al, 2007) and have been used in meta-analytic reviews in applied psychology since personality factors are useful predictors of job performance (Hogan and Holland, 2003).

\subsection{Test to measure personality}

There are a number of tests that can be used to indicate personality factors using the Big Five model. These tests are used in meta-analysis to determine workers' personality factors to evaluate their compatibility with a group (Kristof-Brown et al, 2005; Burch and Anderson, 2004) and are widely used to select personnel and form effective groups (Chiocchio and Essiembre, 2009; Dineen et al, 2002). One of such tests is the Belbin test, which is used to form successful groups based on personality traits and roles that each person may contribute to the group (Belbin, 2017). Another is the Myers-Briggs test, which is used to classify personality preference types and identify how people make decisions (Rojas, 2008). These tests have been extensively used in applied psychology and allow managers to form compatible groups of workers (Hobman et al, 2003).

\subsection{Compatibility}

A number of studies have demonstrated that personality factors influence the compatibility of a group (Kristof-Brown and Stevens, 2001; Witt, 1998). Compatibility reflects the tendency of a group to have similar ways to work, get along well, get things done, and facilitate group performance (Kristof-Brown and Stevens, 2001). In compatible groups, workers are more willing to communicate, share information, and resolve conflicts effectively, which translates in increased job performance and productivity (Dineen et al, 2002). In other words, a compatible group is a team in which the characteristics of its workers have been well matched (Kristof-Brown and Stevens, 2001). In this case, a compatible group is a crew in which the masons get along well and can work well together and have better productivity rates. The next section illustrates how to use the compatibility to predict productivity. 
Probability Density Function for Predicting Productivity in Masonry Construction Based on the Compatibility of a Crew

\section{PREDICTING PRODUCTIVITY: CASE STUDY}

\subsection{Mathematical framework}

Figure 1 shows the mathematical framework that supports masonry contractors in the process of predicting productivity. To obtain productivity estimates, a series of steps need to be followed (see Figure 1). Firstly, a literature review was performed for definitions of the OCEAN factors. Based on these factors, masons complete a test to indicate and quantify their personality. Based on their personality, the foreman determines a compatibility score for all the possible crew formations. After defining the compatibility score, measurements on-site are conducted to measure the productivity for multiple crews that have the same compatibility score. From the field measurements, the productivity density function is developed, that is, an average productivity can be estimated for crews that share similar compatibility. The distribution, alongside the confidence intervals, can be used to better predict productivity, estimate times of construction, and determine productive crew formations.

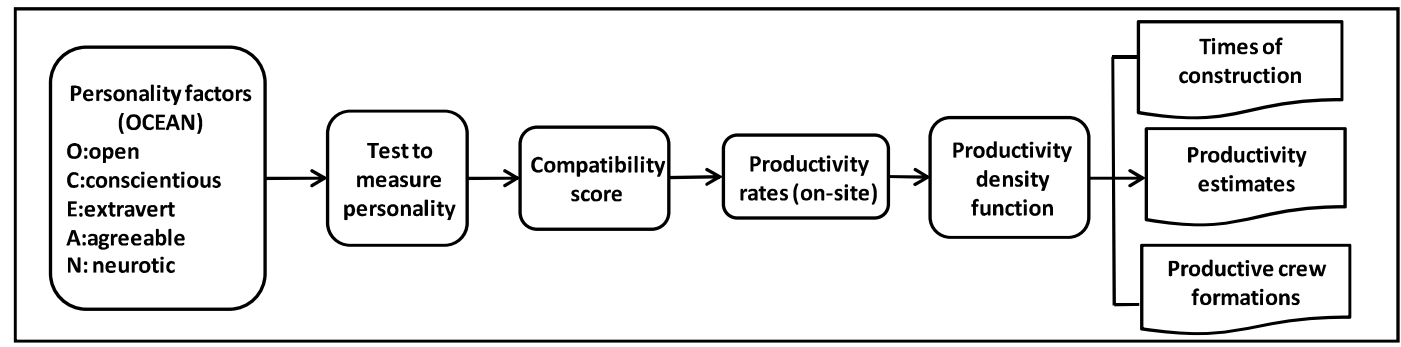

Figure 1: Mathematical framework

\subsection{Personality factors and compatibility scores}

To illustrate how the personality of the masons determines the compatibility of a crew and how the compatibility can be used to predict productivity, let's consider a masonry project. Assume the project has two walls (wall 1 and wall 2) and wall 2 can only be started if wall 1 is finished. There are seven masons available $(\mathrm{m} 1, \mathrm{~m} 2, \mathrm{~m} 3, \mathrm{~m} 4, \mathrm{~m} 5, \mathrm{~m} 6, \mathrm{~m} 7)$ to build the walls. The mason's personality factors are known in advance. That is, each mason completed one of the personality tests (stated above) as part of the interview process and its personality is now available to the foreman. Table 1 shows the score for the OCEAN dimensions to indicate quantitatively the personality of each mason. Note that a high score in an OCEAN dimension indicates that a mason has that personality factor.

Table 1. Personality factors for the masons

\begin{tabular}{lccccc}
\hline Mason & $\begin{array}{c}\text { Openness } \\
(\mathrm{O})\end{array}$ & $\begin{array}{c}\text { Conscientiousness } \\
(\mathrm{C})\end{array}$ & $\begin{array}{c}\text { Extraversion } \\
(\mathrm{E})\end{array}$ & $\begin{array}{c}\text { Agreeableness } \\
(\mathrm{A})\end{array}$ & $\begin{array}{c}\text { Neuroticism } \\
(\mathrm{N})\end{array}$ \\
\hline $\mathrm{m} 1$ & 0.10 & 0.70 & 0.10 & 0.90 & 0.90 \\
$\mathrm{~m} 2$ & 0.80 & 1.00 & 0.40 & 0.20 & 0.30 \\
$\mathrm{~m} 3$ & 0.10 & 0.50 & 0.20 & 0.80 & 0.80 \\
$\mathrm{~m} 4$ & 0.40 & 1.00 & 0.80 & 0.90 & 0.20 \\
$\mathrm{~m} 5$ & 0.90 & 0.90 & 0.90 & 0.20 & 0.30 \\
$\mathrm{~m} 6$ & 0.30 & 1.00 & 0.90 & 0.80 & 0.10 \\
$\mathrm{~m} 7$ & 0.30 & 1.00 & 0.90 & 0.80 & 0.10 \\
\hline
\end{tabular}


For instance mason 4 is conscientious, extrovert and agreeable but not open and neurotic. Let's assume that masons with similar characteristics work better than masons with dissimilar characteristics, as stated in some meta-analytic studies (Mach and Baruch, 2015; Witt, 1998). That is, mason 4 will work well with mason 7. Table 2 shows the compatibility score for different crews and its corresponding masons. These scores were determined by using the personality factors shown in Table 1.

Table 2: Compatibility score for crews

\begin{tabular}{ccc}
\hline Crew & Masons & Compatibility \\
\cline { 2 - 3 } c 1 & $\mathrm{~m} 1, \mathrm{~m} 3, \mathrm{~m} 5$ & 0.50 \\
c 2 & $\mathrm{~m} 2, \mathrm{~m} 4, \mathrm{~m} 6, \mathrm{~m} 7$ & 1.00 \\
c 9 & $\mathrm{~m} 1, \mathrm{~m} 3, \mathrm{~m} 4, \mathrm{~m} 7$ & 0.80 \\
c 12 & $\mathrm{~m} 2, \mathrm{~m} 6, \mathrm{~m} 7$ & 0.40 \\
\hline
\end{tabular}

Note that the higher the compatibility score, the better the masons in the crew get along. That is, masons that work well together will have a higher compatibility score, whereas masons that do not work well together will have a lower compatibility score. For instance, crew 2 has a compatibility score of 1.0, since mason 4, mason 6 and mason 7 have similar personality factors and will get along well.

\subsection{Probability density function}

Let's also assume that crew 1 will build wall 1 . Crew 1 has three masons and its compatibility score is 0.5 . On the other hand, wall 2 is build by crew 2 and crew 2 has four masons and a compatibility score of 1.0. The productivity data has been collected empirically for crew 1 and crew 2 (see Table 3 and Table 4). Crew 1 (compatibility of 0.5) lays blocks at the following rates per period of time (see Table 3). Crew 2, (compatibility of 1.0) lays blocks at the following rates (see Table 4):

\begin{tabular}{cc} 
Table 3: Productivity rates for crew & \\
\hline Number of units & Probability \\
\hline 220 & 0.20 \\
250 & 0.30 \\
270 & 0.30 \\
290 & 0.10 \\
300 & 0.10 \\
\hline
\end{tabular}

\begin{tabular}{cc} 
Table 4: Productivity rates for crew & \\
\hline Number of units & Probability \\
\hline 450 & 0.30 \\
470 & 0.30 \\
490 & 0.30 \\
500 & 0.10 \\
\hline
\end{tabular}

These observations should be made in the field by recording the productivity of crews with the same compatibility scores. To simplify our computations, let's assume an exact number of blocks associated to each probability, and not intervals as it should be done. Again, to simplify our computations we will assume that once a crew settles on a productivity rate, it keeps the same rate until the wall is finished. Wall 1 has 500 blocks, and wall 2 has 1000 blocks thus the previous data can be converted into data of how long it will take each crew to finish wall 1 (Table 5) and wall 2 (Table 6), respectively.

We then can compute the mean and variance for the units of time it takes each crew to finish its respective wall, so for crew 1 we have that the random variable that gives the amount of time that it will take to complete wall 1, we shall call X, has a mean of X $=1.948$ units of time, whereas the random variable that gives the amount of time that crew 2 takes to complete wall 2, we shall call $\mathrm{Y}$, has a mean of $\mathrm{Y}=2.117$ units of time. 
Probability Density Function for Predicting Productivity in Masonry Construction Based on the Compatibility of a Crew

Table 5: Prediction of time for crew 1

\begin{tabular}{cc}
\hline \multicolumn{2}{c}{ Wall 1 } \\
Time periods & Probability \\
\hline 2.27 & 0.20 \\
2.00 & 0.30 \\
1.85 & 0.30 \\
1.72 & 0.10 \\
1.67 & 0.10 \\
\hline
\end{tabular}

Table 6: Prediction of time for crew 2

\begin{tabular}{cc}
\hline \multicolumn{2}{c}{ Wall 2} \\
Time periods & Probability \\
\hline 2.22 & 0.30 \\
2.13 & 0.30 \\
2.04 & 0.30 \\
2.00 & 0.10 \\
\hline
\end{tabular}

Second we compute the variance of both distributions and we obtain 0.037 and 0.006 for $\mathrm{X}$ and $\mathrm{Y}$, respectively. We want to use a continuous probability density to approximate our probability densities as this allows more general estimates to be made. Now, as we only use the mean and variance as reliable observables and given these two, and the probability density with the highest entropy is the normal with these mean and variance, for the first crew we have the following probability density for the time it takes to complete wall 1:

$$
\operatorname{Px}(x)=\frac{1}{\sqrt{2 \pi * 0.037}} \exp \left(-\frac{(x-1.948)^{2}}{2 * 0.037}\right)
$$

,and for crew 2, the probability distribution for the time it takes to complete wall 2 is:

$$
\operatorname{Py}(y)=\frac{1}{\sqrt{2 \pi * 0.006}} \exp \left(-\frac{(y-2.117)^{2}}{2 * 0.006}\right)
$$

As we have assumed that wall 1 should be completed before starting wall 2, then the two walls are expected to be completed in $\mathrm{x}+\mathrm{y}=1.948+2.117=3.065$ units of time. Now, as the two walls are different and the composition of the crew only matters for the compatibility score it produces, we may assume that the random variables $\mathrm{x}$ and $\mathrm{y}$ are independent, so its probability density is given by:

$$
P x+y(z)=\frac{1}{\sqrt{2 \pi * 0.043}} \exp \left(-\frac{(z-3.065)^{2}}{2 * 0.043}\right)
$$

We can make now more accurate predictions. For instance, the probability that it will take more than 3.5 units of time to complete both walls is given by:

$$
\frac{1}{\sqrt{2 \pi * 0.043}} \int_{3.5}^{\infty} \exp \left(-\frac{(\mathrm{z}-3.065)^{2}}{2 * 0.043}\right) \partial \mathrm{z} \sim 0.018
$$

In other words, the work will be completed in less than 3.5 units of time with a probability of 0.98 (that is, with almost certainty). For more complicated projects, the computations will be more elaborate, but will follow the same spirit. Recall that we define the value of the productivity function at a given compatibility score as the mean of the productivity distribution function for that compatibility score. Then we use this productivity function in the allocation model (Florez, 2015) to compute the average time in which the project should be completed. A similar reasoning to the one presented in this example will help predict time intervals for completion with an assigned probability, but this will be the subject of a forthcoming paper. 


\section{CONCLUSIONS}

Crew formation is the process of determining the size and the composition of crews. In masonry construction, superintendents in the jobsite use a number of factors to determine the masons that will be part of a crew. Personality has been found to be a key parameter to form crews and has been identified that the interpersonal compatibility of a crew influences productivity.

To illustrate how the compatibility of a crew can be used to predict productivity, a mathematical framework has been proposed. The framework describes the methodology to measure the personality of the masons, determine the interpersonal compatibility score of a crew, and use the score to predict productivity.

The proposed productivity density function aims to help contractors estimate times of construction, avoid crew conflicts, and find practical ways to increase productivity. The function is based on the compatibility of a crew and uses personality factors and interpersonal characteristics to quantify productivity. These new considerations should prove useful to masonry contractors and enable them to better estimate times of construction, predict of productivity, and identify effective crew formations. Following this study, the idea is to quantify the compatibility of multiple masonry crews and measure their productivity. By doing so, a productivity function in terms of compatibility can be theoretically determined and be used by contractors to more precisely estimate times of construction and total project costs.

One of the limitations about this methodology is that for simplicity, we are assuming that productivity can be predicted by considering the personal compatibility between the workers in a crew. Other factors that influence productivity, internal and external to the operations, may also need to be considered for better estimating times of construction. Following this study, the idea is to formulate a probability distribution function that considers a more holistic set of factors, including those beyond personality.

\section{REFERENCES}

Belbin (2017). Belbin team roles. Available at: http://www.belbin.com/about/belbin-teamroles/ [Accessed 11 Jan 2017].

Borcherding, J. D., and Alarcon, L. F. (1991). Quantitative Effects on Construction Productivity. The Construction Lawyer, American Bar Association, 11(1), 35-48.

Burch, G. S. J., and Anderson, N. (2004). Measuring person-team fit: Development and validation of the team selection inventory. Journal of Managerial Psychology, 19, 406426.

Campion, M. A., Mumford, T. V., Morgeson, F. P., and Nahrgang, J. D. (2005). Work redesign: Eight obstacles and opportunities. Human Resource Management-New York, 44(4), 367-390.

Chiocchio, F., and Essiembre, H. (2009). Group cohesion and performance: A metaanalytic review of disparities between project teams, production teams, and service teams. Small Group Research, 40 (3), 382-420.

Cohen, S., and Bailey, D. (1997). What makes teams work: Group effectiveness research from the shop floor to the executive suite. Journal of mgmt, 23(3), 239.

Dineen, B. R., Ash, S. R., and Noe, R. A. (2002). A Web of applicant attraction: Personorganization fit in the context of Web-based recruitment. Journal of Applied Psychology, 87 (4), 723-734. 
Probability Density Function for Predicting Productivity in Masonry Construction Based on the

Compatibility of a Crew

Florez, L. (2015). Decision support system for masonry labor planning and allocation considering productivity and social sustainability. Ph. D. Diss, Georgia Institute of Technology, Atlanta GA.

Goldberg, L. R. (1993). The structure of phenotypic personality traits. American Psychologist, 48, 26-34.

Hassanein, A. and Melin, J. (1997). Crew design methodology for construction contractors. Journal of Construction Engineering and Management, 123(3), 203-207.

Hiyassat, M.A., Hiyari, M. A., and Sweis, G.J. (2016). "Factors affecting construction labour productivity: a case study of Jordan". International Journal of Construction Management, 16(2), 138-149

Hobman, E. V., Bordia, P., and Gallois, C. (2003). Consequences of feeling dissimilar from others in a work team. Journal of Business and Psychology, 17, 301-325.

Hogan J, and Holland B. (2003). Using theory to evaluate personality and job-performance relations:A socioanalytic perspective. Journal of Applied Psychology, 88, 100-112.

Kazaz, A., and Ulubeyli, S. (2007). Drivers of productivity among construction workers: Study in a developing country. Building \& Environment 42(5), 2132-2140.

Kristof-Brown, A. L., and Stevens, C. K. (2001). Goal congruence in project teams: Does the fit between members' personal mastery and performance goals matter? Journal of Applied Psychology, 86, 1083-1095

Kristof-Brown, A. L., Zimmerman, R. D., and Johnson, D. J. (2005). Consequences of individuals' fit at work: A meta-analysis of person-job, person-organization, persongroup and person-supervisor fit. Personnel Psychology, 58, 281-342

Mach, M., and Baruch, Y. (2015). Team performance in cross cultural project teams: The moderated mediation role of consensus, heterogeneity, faultlines and trust. Cross Cultural Management, 22 (3), 464-486.

Mitropoulos, P., and Memarian, B. (2012). A Framework of Teamwork Attributes Affecting Workers Safety. 2012 Construction Research Congress, 1400-1409.

Nerwal, N., and Abdelhamid, T. S. (2012). Construction Crew Design Guidelines-A Lean Approach. 20th Annual Conference of the International Group on Lean Construction.

$\mathrm{Ng}$, S.T and Tang, Z. (2010). Labour-intensive construction sub-contractors: Critical success factors. International Journal of Project Management, 28(7), 732-740.

Ones, D., Dilchert, S., Viswesvaran, C., \& Judge, T. A. (2007). In support of personality assessment in organizational settings. Personnel Psychology, 60(1), 905-1027.

Rojas, E.M. (2008). Construction Productivity: A practical guide for building and electrical contractors. JROSS Publishing.

Shuck, B., and Reio, T. G. (2013). Employee Engagement and Well-Being: A Moderation Model and Implications for Practice. Journal of Leadership \& Organizational Studies, 21(1), 43-58.

Witt, L. A. (1998). Enhancing organizational goal congruence: A solution to organizational politics. Journal of Applied Psychology, 83, 666-674. 